\title{
PELATIHAN SMK3 KEPADA SISWA SMKS MUHAMMADIYAH CILEGON DAN SMK AL- INSAN CILEGON UNTUK MENAMBAH WAWASAN DAN MEMBANTU MENJADIKAN SISWA YANG SIAP KERJA
}

\author{
Arif Rahman ${ }^{1}$, Surya Perdana ${ }^{2}$ \\ 1,2 Program Studi Teknik Industri, Universitas Indraprasta PGRI \\ arif.rahman0908@yahoo.com ${ }^{1}$, suryaperdana.st.mm@gmail.com ${ }^{2}$
}

\begin{abstract}
ABSTRAK
Kegiatan ini bertujuan untuk memberikan pemahaman kepada siswa-siswi mengenai Sistem Manajemen Kesehatan dan Keselamatan Kerja (SMK3) untuk menambah wawasan sebelum masuk ke dunia kerja. Target luaran kegiatan ini adalah menghasilkan modul Sistem Manajemen Kesehatan dan Keselamatan Kerja dan juga daftar Alat Pelindung Diri yang sering digunakan di dunia kerja. Metode yang dilakukan dalam pelaksaan abdimas dibagi menjadi dua tahapan, pada tahap pertama dilakukan observasi langsung, yaitu: tim abdimas datang ke lokasi langsung dalam rangka memperoleh data. Hal ini dilakukan pada saat menjelang maupun pada saat kegiatan berlangsung. Tahap kedua. Penyuluhan, yaitu: tim pengabdi mengajarkan dan menerangkan secara langsung perihal materi Sistem Manajemen Kesehatan dan Keselamatan Kerja (SMK3) kepada peserta didik guna mendapatkan tambahan wawasan sebelum memasuki ke dunia kerja. Pengajaran dilakukan 3 kali tatap muka agar peserta didik di SMKS Muhammadiyah Cilegon dan SMK Al-Insan Cilegon menjadi lebih siap menghadapi dunia kerja.

Kata Kunci : Sistem Manajemen Kesehatan dan Keselamatan Kerja (SMK3), produktivitas perusahaan, kecelakaan kerja.
\end{abstract}

\begin{abstract}
This activity aims to provide understanding to students about the Occupational Health and Safety Management System (SMK3) to add insight before entering the workforce. The output of this activity is to produce a Health and Safety Management System module and also a list of Personal Protective Equipment that is often used in the world of work. The method carried out in the implementation of the abdimas is divided into two stages, in the first stage direct observation is carried out, namely: the abdimas team comes to the location directly in order to obtain data. This is done both before and during the activity. The second stage. Counseling, namely: the service team teaches and explains directly about the material of the Occupational Health and Safety Management System (SMK3) for students to gain additional insight before entering the workforce. Teaching is conducted 3 times face to face so that students at SMKS Muhammadiyah Cilegon and SMK Al-Insan Cilegon become more ready to face the world of
\end{abstract} work.

Keywords: Occupational Health and Safety Management System (SMK3), company productivity, work accidents.

\section{A. PENDAHULUAN}

Dampak perdagangan global saat ini membuat persaingan sangat ketat dalam berbagai aspek khususnya tentang ketenaga kerjaan yang mempersyaratkan adanya perlindungan atas K3. Untuk meningkatkan efektifitas perlindungan keselamatan dan kesehatan kerja, tidak lepas dari upaya pelaksanaan keselamatan dan kesehatan kerja yang terencana, terukur, terstruktur, dan terintegrasi melalui SMK3 (Sistem Manajemen 
Keselamatan dan Kesehatan Kerja) untuk menjamin agar tercipta suatu sistem K3 yang baik di tempat kerja dengan melibatkan semua unsur yang melibatkan pihak manajemen, pekerja/buruh, dan/atau serikat pekerja/serikat buruh untuk mencegah dan mengurangi kecelakaan kerja dan penyakit akibat kerja serta terciptanya tempat kerja yang nyaman, efisien dan produktif.

Menurut John Ridley (2008) menyebutkan bahwa semua sistem manajemen keselamatan dan kesehatan kerja (SMK3) bertujuan untuk penanganan dan identifikasi risiko K3 yang ada dalam perusahaan agar kejadian yang tidak diinginkan dapat dicegah, sementara itu Soehatman Ramli (2010) menyebutkan bahwa tujuan utama penerapan sistem manajemen K3 adalah untuk mengurangi atau mencegah kecelakaan yang mengakibatkan cedera atau kerugian materi. Penerapan pencegahan kecelakaan kerja pada industri yang berada di Indonesia terdapat berbagai kendala, diantaranya pola pikir yang masih tradisionil dimana mereka menganggap suatu kecelakaan merupakan bagaian dari musibah, sehingga dampaknya para pekerja menjadi pasrah.

Keberhasilan penerapan SMK3 di perusahaan sebetulnya dapat dilihat dari salah satu tujuan penerapannya yaitu untuk mengurangi terjadinya kasus-kasus kecelakaan kerja di tempat kerja. Sedangkan faktanya dapat dilihat bahwa ternyata dari tahun ke tahun angka kecelakaan kerja di Indonesia masih sangat tinggi. Berdasarkan data Jamsostek, menunjukkan bahwa jumlah kecelakaan kerja yang terjadi memang masih sangat tinggi, pada tahun 2011 telah terjadi kecelakaan kerja sebanyak 99.491 kasus, pada tahun 2012 terjadi sebanyak 103.074 kasus, dan pada tahun 2013 terjadi kecelakaan kerja sebanyak 103.285 kasus, dari data pada tahun 2011 hingga 2013 jumlah kecelakaan kerja yang terjadi meningkat dengan rata-rata peningkatan kejadian sebesar $1,76 \%$ setiap tahunnya.

Proses terjadinya kecelakaan kerja melibatkan 4 (empat) unsur produksi yang terdiri dari People, Equipment, Material, Environment (PEME), dimana keempatnya saling berinteraksi dan saling terhubung untuk bersama-sama menghasilkan suatu produk atau jasa. Kecelakaan kerja yang terjadi selama proses interaksi tersebut misalnya ketika kontak antara manusia dengan alat, material, dan lingkungan tempat bekerja. Kecelakaan dapat terjadi karena kondisi alat atau meterial yang kurang baik atau berbahaya. Kecelakaan juga dapat dipicu oleh kondisi lingkungan kerja yang tidak aman melampaui ambang batas. Selain itu, kecelakaan kerja juga bisa bersumber dari 
pekerja itu sendiri yang melakukan aktivitas di lingkungan kerja dan menggunakan alat atau material ditempat tersebut (Soehatman Ramli, 2010:30).

\section{B. LANDASAN TEORI}

\section{Sistem Manajemen Kesehatan dan Keselamatan Kerja}

Keselamatan dan kesehatan kerja (K3) merupakan suatu pendekatan yang menentukan suatu standar secara menyeluruh dan bersifat spesifik, untuk menentukan kebijakan pemerintah atas praktek yang dikerjakan di perusahaan dan dilaksanakan melalui surat panggilan, berupa denda dan hukuman-hukuman lain (Flippo, 1995). Sedangkan Sistem manajemen kesehatan dan keselamatan kerja (SMK3) merupakan bagian dari suatu sistem manajemen yang terdiri dari suatu organisasi, perencanaan sistem, penentuan tanggung jawab pelaksanaan, langkah prosedur proses dan penentuan sumber daya. Sumber daya sendiri sangat dibutuhkan bagi pengembangan SMK3, penerapan SMK3, pencapaian SMK3, hingga pengkajian pemeliharan kebijakan kesehatan dan keselamatan kerja. Pelaksanaan sistem manajemen kesehatan dan keselamatan kerja dilakukan dalam rangka pengendalian resiko yang berkaitan dengan kegiatan kerja agar tercipta tempat kerja yang aman dan produktif (Sastrohadiwiryo, 2005).

Strategi untuk mengembangkan SMK3 terbagi menjadi tujuh bagian yaitu peraturan perundang-undangan yang berlaku, kebijakan, organisasi, rencana SMK3, penerapan SMK3, mengukur dan memantau, dan audit sistem manajemen kesehatan dan keselamatan kerja. Mengenai penerapan undang-undangan dan standar tentang SMK3 yang berada di perusahaan disusun oleh tim khusus yang dibentuk oleh manajemen perusahaan. Hasil yang didapat dari lapangan kemudian disusun dalam suatu peraturan dan pedoman pelaksanaan K3 pada perusahaan (Azmi, 2009).

K3 pada perusahaan menegaskan keterkaitan antara perusahaan terhadap pelaksanan K3. Kesehatan dan keselamatan kerja pada perusahaan harus sesuai dengan operasi perusahaan, melindungi keselamatan dan kesehatan semua pekerja. Sususnan organisasi pada kesehatan dan keselamatan kerja digunakan dalam pelaksanaan kebijakan K3 secara efektif melibatkan peran serta seluruh tingkatan manajemen dan pekerja. Pada posisi top manajemen menempatkan organisasi K3 diperusahaan serta dukungan yang diberikan adalah merupakan pencerminan dari komitmen manajemen terhadap K3 (Azmi, 2009). 
Penyusunan SMK3 perlu diperhatikan dan disusun dengan baik agar SMK3 dapat berjalan dengan efektif demi tercapainya keberhasilan dalam penerapan dan seluruh kegiatan SMK3 dalam berbagai sasaran yang jelas dan dapat diukur dengan baik. Penerapan sistem manajemen kesehatan dan keselamatan kerja dilakukan dengan menyediakan tenaga kerja yang memiliki kualifikasi, sarana yang memadai sesuai. K3 digunakan sebagai pengukur dan pemantau hasil pelaksanaan dengan menggunakan standar yang telah ditetapkan oleh manajemen. Terdapat dua jenis ukuran yang dapat digunakan yaitu pertama ukuran yang bersifat reaktif yang didasarkan pada kejadian kecelakaan dan yang kedua ukuran yang bersifat proaktif karena didasarkan kepada upaya oleh semua sistem melalui hasil audit dan peninjauan secara keluruhan (Azmi, 2009).

\section{Tujuan dan Sasaran Sistem Manajemen Kesehatan dan Keselamatan Kerja}

Tujuan dan sasaran sistem manajemen kesehatan dan keselamatan kerja adalah menciptakan sistem kesehatan dan keselamatan kerja di tempat kerja. Unsur yang terlibat dalam sistem manajemen kesehatan dan keselamatan kerja yaitu tenaga kerja, dan kondisi lingkungan kerja yang terintegrasi dalam rangka mencegah dan mengurangi kecelakaan dan penyakit akibat kerja, selanjutnya dapat terbentuk tempat kerja yang aman bagi pekerja dan hasil yang efisien

\section{Manfaat Sistem Manajemen Kesehatan dan Keselamatan Kerja}

Perusahaan yang menerapkan sistem manajemen kesehatan dan keselanatan kerja akan mendatangkan beberapa manfaat. Manfaat tersebut bagi perusahaan yang menerapkannya adalah pihak manajemen perusahaan akan mengetahui apa saja kelemahan dari unsur sistem operasional perusahaan sebelum terjadi gangguan pada operasional, terjadi kecelakaan, terjadi insiden dan terjadi kerugian lainnya. Gambaran secara jelas dan lengkap tentang kinerja kesehatan dan keselamatan kerja di perusahaan dapat diketahui dengan meningkatkan pemenuhan terhadap peraturan perundangan, meningkatkan pengetahuan, keterampilan dan kesadaran khususnya bagi karyawan yang ikut dalam melaksanakan audit dan terlibat dalam peningkatan produktivitas perusahaan (Syartini, 2010).

\section{Standar Sistem Manajemen Kesehatan dan Keselamatan Kerja}

Standar sistem manajemen kesehatan dan keselamatan kerja yang berlaku di internasional dan nasional. Standar SMK3 secara internasional yang berlaku dan dipergunakan di Indonesia yaitu OHSAS 18001:2007 yang diterbitkan oleh Occupational 
Health and Safety Assessment Series (OHSAS). Standar SMK3 secara internasional lainnya yaitu ILO-OSH 2001 yang diterbitkan oleh International Labour Organization (ILO). Standar sistem manajemen kesehatan dan keselamatan kerja nasional yang berlaku di Indonesia adalah Peraturan Pemerintah No. 50 tahun 2012 (Uajy, 2015).

OHSAS 18001:2007 adalah sebuah standar sistem manajemen kesehatan dan keselamatan kerja yang disusun oleh beberapa organisasi kesehatan dan keselamatan kerja diseluruh dunia. Standar OHSAS 18001:2007 tidak memuat prosedur implementasi, maka dilengkapi dengan OHSAS 18002:2008 sebagai prosedur untuk implementasi OHSAS 18001:2007. Pengembangan OHSAS 18001:2007 disuaiankan dengan dua standar International Standards Organization (ISO), yaitu pertama ISO 9001:2000, merupakan suatu standar tentang sistem manajemen kualitas dan kedua ISO 14001:2004, merupakan suatu standar tentang sistem manajemen lingkungan. Denagn begitu akan mempermudah perusahaan memberikan suatu sistem manajemen terpadu yang saling berhubungan antara kualitas, lingkungan, dan K3. Pada peraturan pemerintah No. 50 tahun 2012 diterangkan mengenai standar nasional tentang penerapan SMK3. PP No. 50 tahun 2012 tersebut berisi tidak hanya mengenai standar, melainkan juga pedoman untuk penerapan dan pedoman untuk penilaian penerapan.

\section{Faktor Penghambat dan Keberhasilan Sistem Manajemen Kesehatan dan Keselamatan Kerja}

Faktor yang dapat menghambat suatu SMK3 dapat dibagi menjadi beberapa poin. Poin pertama yaitu belum tersedia persyaratan yang diajukan konsumen tentang pembuktian penerapan SMK3. Poin kedua yaitu dampak dari krisis ekonomi. Poin ketiga yaitu tidak adanya konsekuensi bagi perusahaan yang melakukan penundaan dan melakukan penolakan terhadap pelaksanaan audit SMK3. Poin keempat yaitu kurang siapanya perusahaan yang disebabkan oleh kurangnya pengetahuan perusahaan tentang SMK3 dan biaya audit bagi perusahaan dianggap cukup memberatkan. Poin kelima frame koordinasi pelaksanaan audit pada departemen teknik lain yang belum dapat terwujud (Azmi, 2009).

Sedangkan faktor keberhasilan penerapan SMK3 yaitu, pertama adalah telah dilakukan penerapan beberapa sistem menejemen yang dapat mendukung terhadap penerapan SMK3. Kedua adalah komitmen yang tinggi kepada K3 dari pucuk manajemen atau induk perusahaan, ketiga adalah perusahaan melakukan studi banding ke perusahaan lain yang telah menerapkan SMK3, keempat adalah adanya tenaga ahli 
dalam perusahaan. Kelima adalah adanya bagian pada perusahaan atau departemen khusus yang menangani K3. Penghargaan di bidang kesehatan dan kesehatan kerja telah didapatkan dari institusi asing (Azmi, 2009).

Selanjutnya faktor keberhasilan lainnya adalah terdapat komite keselamatan yang selalu berperan aktif dalam pelaksanaan K3 di perusahaan. Telah tersertifikasi tuntutan dari pihak konsumen kepada perusahaan untuk menerapkan SMK3. Ketika suatu perusahaan terpacu di dalam sektornya karena perusahaan lain telah berhasil menjalankan SMK3. Upaya pembinaan mengenai sistem manajemen kesehatan dan keselamatan kerja baik dari asosiasi profesi atau dari pembina kawasan perusahaan (Azmi, 2009).

\section{Penerapan Sistem Manajemen Kesehatan dan Keselamatan Kerja}

Di dalam OHSAS terdapat model SMK3 yang tertulis dalam OHSAS 18001 : 2007 yang membahas tentang standar SMK3. Standar OHSAS berdasarkan pada metodologi Plan-Do-Check-Act (PDCA). Dalam Plan atau perencanaan perusahaan akan menentukan tujuan dan proses yang diperlukan agar memberikan hasil sesuai dengan kebijakan K3 yang ada pada perusahaan. Dalam Do atau pelaksanaan perusahaan akan mengimplementasikan semua proses yang sebelumnya telah direncanakan (Uajy, 2015).

Dalam Check atau pemeriksaan suatu perusahaan akan memantau pelaksanaan K3 dan menilai seluruh proses pelaksanaan K3 berdasarkan kepada kebijakan perusahaan, tujuan dari K3, standar tentang K3 serta segala persyaratan lainnya, dan melakukan pelaporan tentang hasilnya kepada manajemen. Dalam Act atau pengambilan tindakan perusahaan akan mengambil suatu tindakan dalam meningkatkan performansi K3 secara berkesinambungan (Uajy, 2015). DEPNAKER mengeluarkan kebijakan mengenai K3 agar perusahaan melakukan pendekatan preventif dimulai dari tahap pemilihan teknologi dan tahap penerapan prosedur yang baik (Aditama, 2006).

\section{METODE PELAKSANAAN}

Kegiatan pelatihan Sistem Manajemen Kesehatan dan Keselamatan Kerja ini dilaksanakan di SMKS Muhammadiyah Cilegon dan SM Al-Ihsan Cilegon. Kegiatan abdimas ini dilakukan dengan metode penyuluhan, diskusi, dan juga tanya jawab oleh siswa-siswi. 
1. Tahapan Pelaksanaan

Kegiatan pengabdian masyarakat ini dimulai dari bulan Oktober 2017 sampai dengan Desember 2017, dengan tahapan sebagai berikut:

a. Melakukan survey ke sekolah dan diskusi dengan kepala sekolah mengenai materi yang sesuai untuk siswa-siswi mengenai Sistem Manajemen Keselamatan dan Kesehatan Kerja (SMK3)

b. Proses persiapan sosialisasi pelatihan Sistem Manajemen Keselamatan dan Kesehatan Kerja (SMK3) kepada siswa SMKS Muhammdiyah Cilegon dan SMK AlInsan Cilegon.

c. Melakukan penyuluhan kepada siswa-siswi dengan metode diskusi dan tanya jawab

2. Pelaksanaan Kegiatan

Kegiatan abdimas ini dilakukan atas dasar izin dari pihak sekolah, yaitu SMKS Muhammadiyah dan SMK Al-Ihsan Kota Cilegon. Kegiatan abdimas ini diawali dari dengan observasi lapangan untuk mengetahui kondisi sekolah dan kurikulum yang diajarkan di sekolah tersebut. Hal ini dimaksudkan pelaksaan abdimas disesuaikan dengan kebutuhan siswa-siswi, dan juga kondisi guru, jadwal, dan fasilitas yang ada di sekolah.

Kegiatan berikutnya adalah melakukan penyuluhan sosialisasi mengenai Sistem Manajemen Kesehatan dan Keselamatan Kerja dengan menggunakan infocus, agar siswa-siswi dapat melihat, dan bisa memahami penyuluhan yang disampaikan oleh Team Abdimas. Kegiatan dilaksanakan di dalam kelas. Sesmua siswa belum pernah mengetahui mengenai Sistem Manajemen Kesehatan dan Keselamatan Kerja (SMK3), penyuluhan ini merupakan hal yang baru buat para siswa sehingga yang bertugas sebagai presentator harus menjelaskan dari awal, pengertian, maksud, tujuan, dan manfaat dari SMK3 secara detail dan rinci supaya para siswa bisa dengan mudah memahami materi yang disampaikan.

Berdasarkan hasil penyuluhan yang telah dilaksanakan kepada siswa-siswi di sekolah, maka dilakukan sesi tanya jawab antara siswa dengan team abdimas. Hasil yang kami amati bahwa para siswa sangat antusias dengan materi yang disampaikan, hal ini terbukti dengan banyaknya pertanyaan yang diajukan oleh para siswa kepada team abdimas. 


\section{HASIL DAN PEMBAHASAN}

\section{Hasil}

Kegiatan pelatihan Sistem Manajemen Kesehatan dan Keselamatan Kerja (SMK3) untuk memberikan tambahan wawasan kepada siswa-siswi SMKS Muhammadiyah dan SMK Al-Ihsan di kota Cilegon- Banten, yang dilakukan oleh team abdimas dari Universitas Indraprasta PGRI Jakarta yang beranggotakan 4 (empat) orang. Kegiatan dilaksanakan terhadap siswa-siswi di ruang kelas. Kegiatan ini diawali dengan observasi dua mitra tersebuat pada bulan Oktober 2018 untuk mengumpulkan informasi, menganalisa masalah dan mengidentifikasikan segala yang berkaitan dengan siswa.

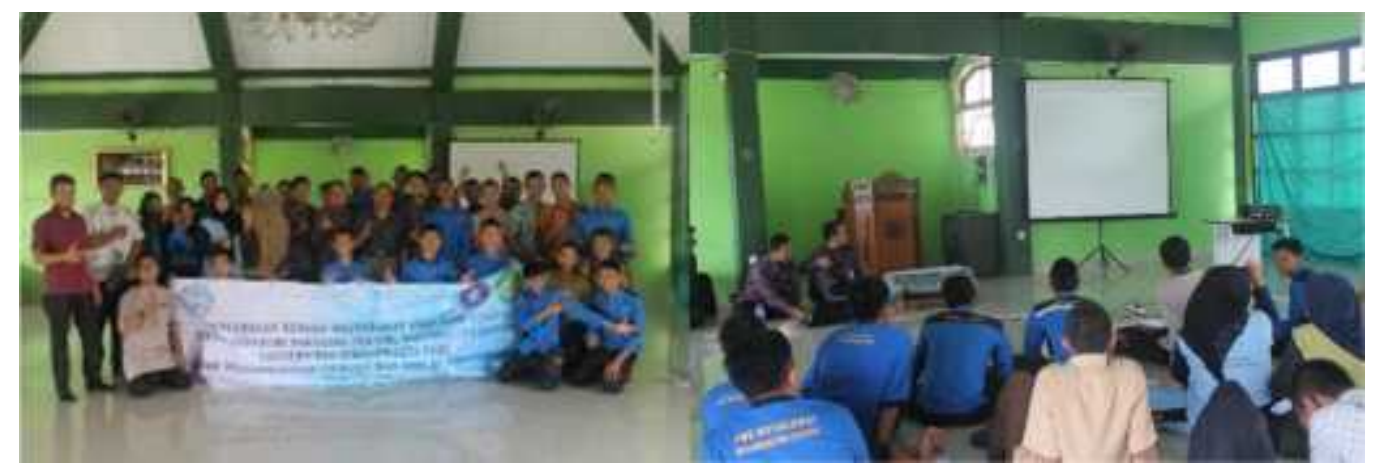

Gambar 1. Sosialisasi kepada siswa-siswi SMKS Muhammadiyah

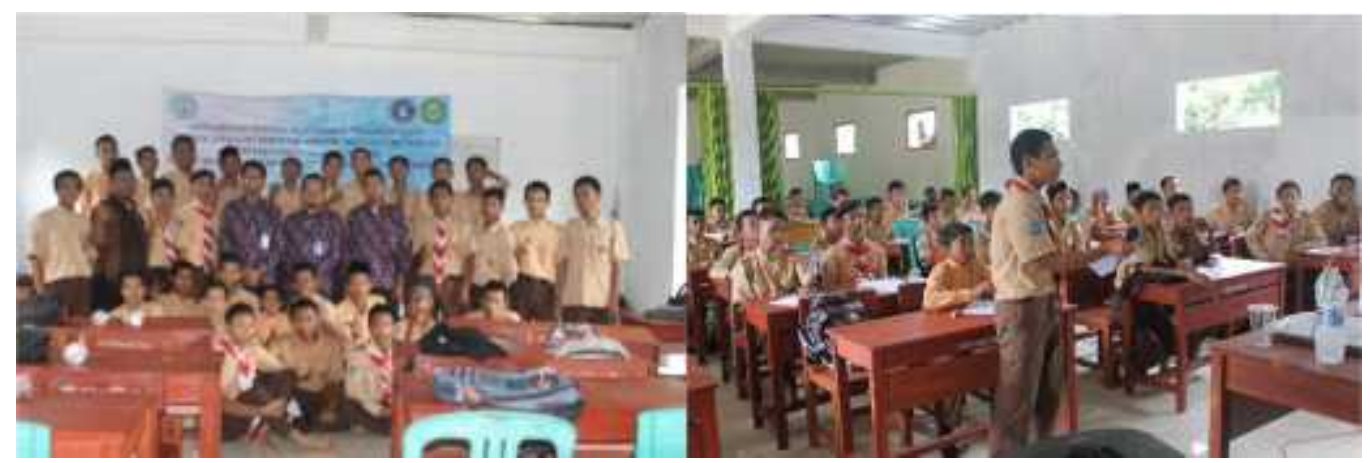

Gambar 2. Sosialisasi kepada siswa SMK Al-Ihsan di kota Cilegon

Di bulan November minggu pertama, tim abdimas melakukan pembuatan materi untuk memudahkan penyuluhan pembelajaran. Pada bulan November minggu ketiga melaksanakan penyuluhan kegiatan pembelajaran. Berdasarkan sosialisasi kegiatan penyuluhan ini, diperoleh hasil sebagai berikut: [1]. Siswa-siswi sangat antusias dengan materi yang disampaikan oleh team abdimas; [2]. Siswa-siswi mendapatkan wawasan 
baru mengenai SMK3 sehingga para peserta didik bisa lebih siap dalam menghadapi dunia kerja.

\section{Pembahasan}

Kegiatan pelatihan SMK3 yang dilakukan sangat bermanfaat sekali bagi SMKS Muhammadiyah Cilegon dan juga SMK Al-Insan Cilegon, dengan pelatihan ini diharapkan bisa menambah wawasan dan pengetahuan dari masing-masing peserta. Dukungan dari Kepala Sekolah SMKS Muhammdiyah dan juga SMK Al-Insan dalam memberikan dukungan agar para siswanya mendapatkan pelatihan yang bermanfaat dan antusias dalam mengikuti kegiatan ini patut diapresiasi, mulai dari perkenalan, penyampaian materi sampai akhir pelatihan.

Dengan penambahan wawasan/pengetahuan mengani SMK3, sehingga secara keseluruhan proses kegiatan abdimas dapat terlaksana dengan baik. Dapat disimpulkan bahwa kegiatan ini dapat meningkatkan kemampuan, pengetahuan, wawasan dan motivasi siswa SMKS Muhammdiyah dan SMK Al-Insan dalam mengahdapi persaingan di dunia kerja nanti setelah lulus sekolah.

\section{E. KESIMPULAN}

Berdasarkan hasil pelaksanaan pengabdian pada masyarakat yang telah dilaksanakan di SMKS Muhammadiyah dan SMK Al-Ihsan Kota Cilegon, maka dapat disimpulkan hai-hal sebagai berikut:

1. Dapat meningkatkan kemampuan, pengetahuan, wawasan dan motivasi siswa SMKS Muhammdiyah dan SMK Al-Insan Kota Cilegon dalam mengahdapi persaingan di dunia kerja nanti setelah lulus sekolah

2. Kegiatan abdimas ini membutuhkan dukungan semua pihak, termasuk sekolah, dan juga dinas terkait untuk dapat memfasilitasi dan menyediakan pelatihan Sistem Manajaemen Kesehatan dan Keselamatan Kerja bagi para peserta didik.

\section{F. DAFTAR PUSTAKA}

Aditama. (2006). Kesehatan dan Keselamatan Kerja. Jakarta: Universitas Indoensia.

Atmoko, Tjipto. (2015). Standar Operasional Prosedur (SOP) dan Akuntabilitas Kinerja Instansi Pemerintah. Tersedia di http://edokumen.kemenag.go.id/files/BX32jRZz1284857253.pdf. Diakses 26 September 2017. 
Azmi, Rahimah. (2009). Penerapan Sistem Manajemen Keselamatan dan Kesehatan Kerja oleh P2K3 untuk Meminimalkan Kecelakaan Kerja di PT. Wijaya Karya Beton Medan Tahun 2008. Medan. Universitas Sumatera Utara. http://repository.usu.ac.id/bitstream/123456789/14644/1/09E01016.pdf. Diakses tanggal 6 Mei 2015.

Flippo, Edwin. (1995). Manajemen Personalia Edisi Keenam. Jakarta: Erlangga.

Griffin, W. Ricky. (2004). Manajemen, Edisi 7 Jilid 1. Jakarta: Erlangga.

Mangkunegara, Anwar Prabu. 2002. Manajemen Sumber Daya Manusia. Bandung: PT Remaja Rosda Karya.

Ramli, Soehatman. (2010). Sistem Manajemen Keselamatan \& Kesehatan Kerja OHSAS 18001. Jakarta: Dian Rakyat.

Ridley, John. (2008). Ikhtisar Kesehatan \& Keselamatan Kerja Edisi Ketiga. Jakarta: Erlangga.

Sastrohadiwiryo, Susanto. (2005). Manajemen Tenaga Kerja Indonesia. Jakarta: Bumi Aksara.

Siswanto, Hari dan Teguh Arifianto. (2006). Penerapan K3 Proyek Gedung di PT. Hutama Karya Wilayah IV. Semarang. Universitas Diponegoro. http://eprints.undip.ac.id/34174/5/1665 chapter II.pdf. Diakses tanggal 6 Mei 2015.

Suma'mur P.K, Dr, Msc. (1981). Keselamatan Kerja dan Pencegahan Kecelakaan. Jakarta: PT Toko Gunung Agung.

Supranto, J. (2000). Statistik Teori dan Aplikasi, edisi ke-6. Jakarta: Erlangga.

Syartini, Titi. (2010). Penerapan SMK3 dalam Upaya Pencegahan Kerja di PT. Indofood CBP Suskes Makmur Divisi Noodle Cabang Semarang. Surakarta. Universitas Negri Surakarta. 